Brooks, by E. A. Andrews. Hutchinson and Co.-Photography (Concise Knowledge Library), edited by H. P. Maskell and others; The Wonders of the World, in parts, illustrated. Crosby Lockwood and Son.-Short Specifications of Materials, Labour, and Goods for Works Connected with Building, J. Cubitt; Houses, Villas, and Bungalows for Britishers and Americans Abroad, G. G. Samson. Longmans and Co._A History of the Cavendish Laboratory, Cambridge, Various Writers, illustrated. Macmillan and Co., Ltd.-Tennyson as a Student and Poet of Nature, Sir Norman Lockyer, K.C.B., F.R.S., and W. L. Lockyer, with an introduction and notes; The Conservation of Natural Resources in the United States, C. R. Van Hise, illustrated. John Murray.British Weights and Measures, as described in the Laws of England from Anglo-Saxon Times, Col. Sir C. M. IVatson. Kegan Paul and Co., Ltd.-Educational Psychology, Prof. E. L. Thorndike. Swan Sonnenschein and Co., Ltd.-A translation of Hegel's Phenomenology of Mind, J. B. Baillie, 2 vols.; Thought and Things: a Study of the Development and Meaning of Thought or Genetic Logic, Prof. J. M. Baldwin, vol. iii., Real Logic; Matter and Memory, H. Bergson, translated under the author's supervision by N. M. Paul; Adolescence, J. W. Slaughter; Physiological Psychology, Prof. W. Wundt, a translation of the fifth and wholly rewritten German edition by Prof. E. B. Titchener, in 3 vols., vol. ii., illustrated; and new editions of The History of Asthetic, Dr. B. Bosanquet; Riddles of the Sphinx: a Study in the Philosophy of Humanism, Dr. F. C. S. Schiller; Darwinism and the Humanities, Prof. J. M. Baldwin (Ethical Library). Williams and Norgate.-A popular edition of Herbert Spencer's First Principles, 2 vols.

\section{THE INTERNATIONAL CONGRESS ON} RADIOLOGY AND ELECTRICITY.

THE second congress on radiology and electricity was held at Brussels on September $13-15$. That two congresses have already been held to consider questions relating to radio-activity and allied subjects affords evidence of the rapid progress in this branch of science of recent years; but that some five hundred workers in physics and medicine should have assembled to discuss the bearing of modern electrical theory and radio-activity upon the various investigations on which they are engaged is a striking proof of the influence which these new ideas have exercised on the progress of science. It is now universally felt to be desirable, if not necessary, that those engaged on investigations in radio-activity in different parts of the world should have occasional opportunities of meeting each other, and perhaps one of the most important results of the recent congress has been the formation of an influential international committee to arrange the time and place of subsequent congresses. The continuation at regular intervals of meetings such as the one which has just taken place is therefore now assured, and thanks are due to the Belgian men of science and to the Belgian Government, under the patronage of which the congress was held, for organising the two successful meetings, the first at Liége in 1905 and the second at Brussels this year. It may be added that the meeting was rendered the more successful and pleasant by the hospitality offered to members by the town of Brussels. In this connection may be mentioned the reception at the Bourse and at the Town Hall by the Municipality, and also the admirable performance at the Theâtre Royal de la Monnaie, at which members were invited to be present.

The work of the congress began on Tuesday, September 13, with a meeting at the Palais des Fêtes in the exhibition grounds, when members assembled to hear an address by the president, Prof. de Heen, on ather and matter. The large gathering included eminent men of science from all parts of the world. The opening meeting finished, members dispersed to spend the remainder of the morning in the exhibition, after which they reassembled in the buildings of the Free University for a meeting which proved of exceptional interest. The proceedings began with a discussion, opened by Prof. Rutherford, on the question of fixing a suitable nomenclature in radio-activity and of establishing radio-active standards adapted to the requirements of quantitative measurements to be made for physical and medical purposes. After a short discussion it was decided that the matter could best be settled by a small committee acquainted with the needs of the different branches of the subject, and that this committee should meet and report to the congress the results of their deliberations at a subsequent meeting. The report of the committee is of such special interest that it is not possible to deal adequately with it within the limits of this article, but a full account of the recommendations was given by Prof. Rutherford in Nature of October 6. While the necessary arrangements were being made for the formation of this committee the president called upon Madame Curie to give an account of the recent experiments made in Paris to isolate metallic radium. It will be remembered that this metal has hitherto not been separated from its salts, although a radium amalgam was obtained some years ago by Coehn. The beautiful experiments described by Madame Curie, resulting in the isolation of metallic radium, must be regarded as a triumph in chemical manipulation when it is remembered that, in addition to the fact that on account of its chemical properties radium is difficult to isolate, the operations had to be carried out with minute quantities of material in such a way as to avoid loss of the precious substance during the process. These experiments should remove all possible doubt that radium is, in fact, an element belonging to the same group of metals as barium.

After some other communications the meeting adjourned until the following day, when the congress met in three sections to deal with the large number of papers on the physical and medical aspect of radiology. The work of the physical section was of great interest. It began with a lecture, remarkable for the clear and vivid style of its delivery, by M. Perrin, who described his experiments on Brownian movement and their bearing on the determination of atomic magnitudes, followed by a review of the present position of our knowledge of these matters. Dr. Hahn next gave an account of the method of preparation of some highly active samples of radiothorium and mesothorium, of which specimens were shown. The phosphorescent effects produced by them on a zinc-sulphide screen could be clearly seen from all parts of the lectureroom, and there can be no doubt that these products, which are now to be had from Messrs. Knöffler and Co., of Berlin, will prove of great use for many purposes as an alternative to radium. Mr. Soddy, followed with a description of the results of his work on the rate of production of helium from a Portuguese specimen of autunite. From his experiments it is possible to assign limits between which must lie the "life" of ionium, that stable product discovered by Boltwood, and known to be the parent of radium.

The papers which remained to be read on the last day were so numerous that it was found necessary at the last moment to subdivide the meeting further, and a separate section was quickly formed under the presidency of Prof Rutherford for the discussion of purely radio-active questions. A number of important papers on various subjects were read. The proceedings were opened by Prof. Brago with a discussion of the nature of the $\gamma$ rays, in which he showed how it is possible to assign a "range" to the path of $\beta$ rays in different metals on the assumption that the $\gamma$ rays are material particles, and that the ionisation produced by them is due to $\beta$ rays produced in their path. The paper was immediately succeeded by one by Prof Barkla, who explained how each element submitted to a stream of homogeneous X-rays emits several beams of homogeneous X-rays characteristic of the element. Each homogeneous radiation was excited by a primary radiation of greater penetrating power according to Stokes's law for fluorescence, so that it was possible to draw a close comparison between light and X-rays in this respect. Dr. Hahn then gave an account of his experiments with $\mathrm{Dr}$. Baeyer on the magnetic deflection of $\beta$ rays. Photographs were shown indicating that the deflected rays from single radio-active product gave rise to definite lines on the photographic plate, showing that during the decay of radio-active substances, just as for the $\alpha$ particle, the $\beta$ particles leave the atom with a velocity characteristic of the particular product. The question of the recoi ${ }^{1}$ of

NO. 2 I 37 , vOL. 84$]$ 
radio-active matter during the expulsion of an $\alpha$ particle was next discussed by Dr. Makower. Experiments made by Dr. Russ, Mr. Evans, and himself on the electric and magnetic deflection of radium $B$ when it recoils made it possible to determine the charge carried by the atoms of radium $\mathrm{B}$, and to determine its atomic weight. The results showed that the atomic weight had approximately the value to be expected on the disintegration theory of radio-active changes. $M$. Wertenstein followed with a description of his work on the absorption by air of radium $\mathrm{B}$ when it recoils. Dr. Kovarik then gave a short account of his investigations on the absorption and scattering of $\beta$ rays. It was shown how entirely erroneous results might be obtained in determining the absorption of $\beta$ rays by matter unless certain precautions were taken in making the measurements. Dr. Kleeman next brought before the meeting some theoretical considerations regarding the absorption of $\alpha, \beta$, and $\gamma$ rays in passing through matter, after which $M$. Moulin described his interesting experiments on the saturation currents obtained in air ionised by $a$ rays when the electric field is inclined at different angles to the trajectories of the rays.

It has only been possible to deal even shortly in this article with the papers on radio-activity, which formed perhaps the most important part of the work of the congress; but communications were presented on almost all branches of modern physics, amongst which some of the most interesting may be mentioned. Dr. Conway gave a paper on the theory of electronic conduction; Prof. Becquerel described his experiments on magneto-optic phenomena in crystals; Prof. Wien discussed the existence of positive and negative ions in canal rays; Prof. Arrhenius dealt with the solubility of the active deposit of actinium; Prof. Weiss spoke of molecular magnetic fields; and Prof. Exner gave a description of the new Radium Institute at Vienna.

The papers read before the biological section of the congress were so decidedly medical in character that an account of them would scarcely be of interest to readers of Nature.

W. M.

THE OPENING OF THE MEDICAL SESSION. THE custom of opening the winter session, the com1 mencement of the medical year, at the medical schools with addresses has much to commend it. The attention of the public is directed to the work, scientific and charitable, of the great hospitals; if the address is delivered by a layman, the lay views on medical education and things medical are expressed, often with advantage; if by a medical man, the students hear words of wisdom culled from a ripe experience.

In the absence of the chairman, Prince Francis of Teck, the gathering at the Middlesex Hospital was presided over by Lord Grenfell, and the address was delivered by Lord Kitchener, who naturally dealt with the relation of medicine to the army and with army medical organisation. He directed attention to the improved sanitary condition of the army and to the vast field still remaining for research. As regards India, he said:- "That scourge of the army-enteric fever-is now at last definitely yielding to improved sanitary methods and to the system of inoculation which has recently become almost universal. Enteric will before long, I feel sure, join the formerly dreaded cholera in total banishment from our barracks. To bring home to you the measure of success which has attended their work in India, I need only point out that during the last ten years the ratio of 'constantly sick, invalided, and deaths 'has been reduced by no less than 50 per cent. But there still remains in that country a vast field for your energies and painstaking research."

As regards army medical organisation, Lord Kitchener pointed out that the training which turns out competent medical men for civil work is quite inadequate in equipping medical officers for the special needs of the army in war time.

At St. Mary's Hospital Sir Arthur Conan Doyle gave an address to the students on "The Romance of Medicine." After relating some of his medical experiences in his early days, he pointed out that "there were, perhaps, some dangers which came from a medical training, but

NO. 2 I 37 , VOL. 84.] there was a great post-graduate course called life, and in that course one learnt to correct these weaknesses. One was an undue materialism. $\mathrm{He}$ was educated in. a materialistic age, before psychical research, scientific hypnotism, telepathy, and other such agencies emphasised the possibilities which lie outside the things that we can see, handle, and explain. They looked upon mind and spirit as secretions from the brain in the same way as bile was a secretion of the liver. Brain centres explained everything, and if you could find and stimulate the centre of holiness you would produce a saint--but if your electrode slipped and you got on to the centre of brutality, you would evolve á Bill Sikes. That was, roughly, the point of view of the more advanced spirits among them."

In the concluding portion of his address Sir Conan Doyle dealt with medicine and history and some of the modern developments of medicine, particularly the rôle of opsonins. The starting point of the opsonin investigation was when it was shown that a white corpuscle taken out of the blood plasma would not digest microbes, and would oniy renew its activities when it was moistened with that fluid. This experiment showed that in that fluid there was suspended some invisible stuff which increased the activity of the white corpuscle, and made it devour microbes-some sort of sauce, in fact, which made the microbes more attractive to it. This substance was named opsonin. It had been found that, normally, opsonins are present in fixed quantity, but that in microbial infections the opsonins are generally diminished in amount. By the injection of dead microbes the activity of the white blood corpuscles is stimulated, more opsonin is formed, and the disease process tends to be cured.

At Charing Cross Hospital the Huxley memorial lecture constituted the opening address, and was delivered by Dr. Mott, F.R.S., the subject being "The Hereditary Aspects of Nervous and Mental Diseases." He remarked that in certain nervous diseases it is generally recognised that heredity plays a part, but these are due to characteristic morphological defects. As regards insanity, there are few alienist physicians who do not hold a strong belief in hereditary causation. The matter is now being investigated statistically, and a report will shortly be published. Consanguinity does not appear to produce insanity or nervous disease provided both stocks are free from taint. Chronic alcoholism figures largely in the pedigrees of patients admitted to asylums, but the idea that a desire for alcohol is transmitted from parent to offspring is erroneous-what is transmitted is lack of will power and moral sense.

The Dean of Salisbury delivered the address at University College Hospital. He emphasised the importance of complete development in a sound education. An address on "Woman's Sphere in Medicine" was given by Mr. E. W. Roughton at the London School of Medicine for Women. Mr. Roughton said that there were cogent reasons why there should be a female section of the profession. So far as he was able to judge, in suitability, adaptability and other characters, and in intellectual capacity, women would compare equally with men in the profession. There were, of course, some divergences between the sexes; women, for instance, did not, as a rule, seem to be so handy as men in looking after pieces of mechanism.

At the London Hospital Dr. Robert Hutchison gave the annual "Schorstein "lecture to the students of the medical school, the subject being "Congenital Pyloric Stenosis." Prof. Marett Tims delivered the address at the Royal Veterinary College. He pointed out the growing importance of biology with regard to the problems of medical and veterinary science, and suggested the establishment of a bureau at the Royal Veterinary College for the collection of statistics, the working out of all questions of inheritance in animals, not only the inheritance of disease, but also of data desirable from the point of view of the breeder, especially in the question of horse-breeding.

Prof. Howard Marsh, master of Downing College, Cambridge, distributed the prizes in the University of Leeds. In his address he dealt with the problems of medical education. He said that as medicine had now become a department of biology, its pursuit necessarily demanded a sound acquaintance with the broad principles of those 